\title{
A Cascaded Tunable Wide Stop Band Frequency Selective Surface with High Roll-off Band Edge
}

\author{
Snehasish SAHA, Nurnihar BEGAM, Sushanta BISWAS, Partha Pratim SARKAR
}

Dept. of Engineering and Technological Studies, University of Kalyani, Kalyani, India

snehasishsaha.eie@gmail.com,nur.ice40@gmail.com, biswas.su@gmail.com, parthabe91@yahoo.co.in

Submitted June 23, 2020 / Accepted February 4, 2021

\begin{abstract}
A three-layer wide-band reflective Frequency Selective Surface (FSS) reflector with a high roll-off band edge is proposed in this paper. Each layer of the structure is patch type FSS. The proposed FSS has merits of wideband response over $S$ band and lower $C$ band with bandwidth of $3.6 \mathrm{GHz}$ for transmission $<-10 \mathrm{~dB}$ with 94\% bandwidth and significant stability for different incident angles up to 40 degree. The polarization insensitivity of the FSS also added an extra dimension of the structure. The simulation process as well as the experimental measurement process and ECM (equivalent circuit model) analysis of the FSS have been done. The good agreement in simulated, measured and ECM results verifies the wide stop band for the proposed FSS. The tunable and switchable transmission behavior of the FSS for variation in width of the internal air gap and lateral sliding of the middle layer of the structure respectively are also presented here.
\end{abstract}

\section{Keywords}

Frequency Selective Surface, reflector, wide stop band, roll off, cascade structure, incidence angle stability, polarization insensitivity, equivalent circuit model, tunable and switchable transmission coefficient

\section{Introduction}

Frequency Selective Surface is one type of spatial filter used in radio frequency. It is an arrangement of twodimensional periodic array of metallic patches on a dielectric substrate or apertures with in a metallic sheet. It may reflect back (in case of patch type) or allow to pass (in case of aperture type) certain band or bands of radio frequencies (RF)[1], [2]. Generally they are widely used in various microwave systems like antenna, radome, sub reflector, polarizer, satellite transponder etc [3]. The wide band characteristics (may be band pass or band stop) provided by the FSS are desirable in some applications as it may enhance the gain and directivity of broadband antennas [4-8] when it is incorporated with the antenna. To improve the use of several antennas with different operating frequencies in multifunctional system [9], [10] wide band FSSs are used.
In recent years, research on designing of wide band FSS with wide incidence angle and polarization independence is going on. Besides wideband frequency behavior improvement of selectivity characteristics is one of noticeable demands in that scenario. In [11] the authors prescribed multilayer absorbers and FSS to achieve UWB response. In [12] authors proposed a multilayer FSS (four layers) to improve the gain of a UWB antenna. In [13] authors prescribed three layers of patch type FSS and an ultra wide stop band response is achieved. The roll off determines the selectivity of the operating band. Another type of wide band stop FSS is proposed in [14] by introducing the air spacing between two two-dimensional layers but in that case also out of band response is not so good. A single layer UWB FSS is proposed in [15] where the simulated operating band is $4.6 \mathrm{GHz}-12 \mathrm{GHz}$. But in all the cases roll off of higher and lower band edge is not good enough. To improve the roll off of operating bandwidth different techniques are followed in various research works [16-18]. In [16] a three dimensional band pass FSS formed by cascaded structure of 2D array of shielded microstrip lines with sorted via to ground with multiple transmission zeros has been presented and wide out-of-band rejection in frequency behavior has been recorded. In [17] an FSS with unit cells included with mushroom-like cavity and four Ltype slots etched on the top and bottom layers and sharp band edge is realized. In [18] dual layer FSS with wideband and high selective frequency behavior has been proposed. In this FSS two layers with different unit cell structures are arranged in cascaded manner. But in these cases percentage of operating bandwidth is not very effective.

In this paper a three layer patch type FSS arranged in cascade formation is proposed. This proposed structure provides a wide stop band response with the normalized transmission coefficient below $-10 \mathrm{~dB}$ reference level over wide frequency range of $\mathrm{S}$ band and lower $\mathrm{C}$ band (2.06 to $5.63 \mathrm{GHz}$ ). Thus it may be used as a good reflector with percentage bandwidth of $94 \%$. This structure also offers a good roll off at its downward and upward cut off frequencies. As the design of patches is symmetrical in horizontal and vertical direction, it provides polarization independent transmission response for 90 degree rotational case. This proposed structure also maintains its response for different incident angles of incident wave up to 40 de- 
gree. The performance of the proposed FSS is verified experimentally as well as by analyzing the equivalent circuit model (ECM).

\section{Structural Description and Fabrication Process}

The proposed structure consists of three single layers of Frequency Selective Surfaces (FSS) in cascade arrangement with an air gap of $14 \mathrm{~mm}$ in between two consecutive FSS layers. The complete geometry of unit cell structure is shown in Fig. 1(a). All the layers are patch type in design and they provide band stop properties to radio frequencies. Acrylic sheet with relative dielectric constant $\varepsilon_{\mathrm{r}}=2.8$, loss tangent $(\tan \delta=0.02)$ and thickness $h=2.9 \mathrm{~mm}$ is used as dielectric substrate in all of the FSS layers. To get high roll off band edge in case of FSS layer 1 and FSS layer 3, the geometries in design of patch (aluminum layer) are same and it is shown in Fig. 1(b). Fig. 1(c) shows the design geometry of FSS layer 2. All the dimensions of the proposed structures are described in Tab. 1.

This patch type FSS structure is chosen to achieve good UWB reflection characteristics in the frequency band of 2-6 GHz. In case of layer 1 and layer 3, unit cell dimension is $36 \mathrm{~mm} \times 36 \mathrm{~mm}$ (in order of $0.2 \lambda_{0} \times 0.2 \lambda_{0}$ ), while the patch has the dimension of $32 \mathrm{~mm} \times 32 \mathrm{~mm}$. A square loop type slot and a square shaped slot are introduced to

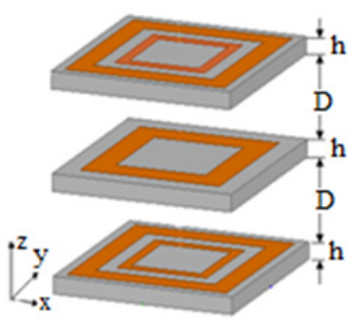

(a)

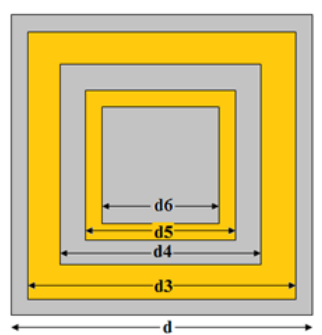

(b)

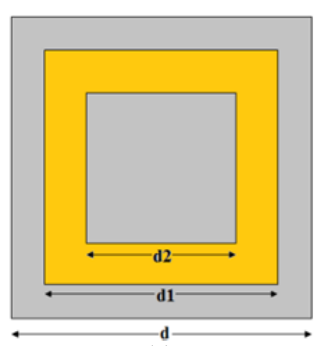

(c)

Fig. 1. (a) Proposed unit cell structure of three layer FSS. (b) Proposed design of layer 1 and layer 3 . (c) Proposed design of layer 2.

\begin{tabular}{|c|c|c|c|}
\hline Parameters & Values (mm) & Parameters & Values (mm) \\
\hline $\mathrm{h}$ & 2.9 & $\mathrm{D}$ & 14 \\
\hline $\mathrm{d}$ & 36 & $\mathrm{~d} 1$ & 28 \\
\hline $\mathrm{d} 2$ & 18 & $\mathrm{~d} 3$ & 32 \\
\hline $\mathrm{d} 4$ & 24 & $\mathrm{~d} 5$ & 18 \\
\hline $\mathrm{d} 6$ & 14 & & \\
\hline
\end{tabular}

Tab. 1. Values of parameters shown in Fig. 1. to reduce the resonating frequency and to achieve dual stop band characteristics. In case of FSS 2 the dimension of unit cell is the same as previous two layers and the dimension of reference square patch is $28 \mathrm{~mm} \times 28 \mathrm{~mm}$. In this case a slot of dimension $18 \mathrm{~mm} \times 18 \mathrm{~mm}$ is introduced. The transmission response of FSS layer 1 and layer 3 are same. When they are arranged in cascade, the transmission response has higher bandwidth and higher roll-off for both the stop bands by maintaining the resonating frequency same. Finally, for the proposed structure (as Fig. 1(a)) an UWB transmission characteristic is achieved.

To verify the transmission characteristics of the proposed FSS structure, a prototype was fabricated by using a laser cutting machine. The aluminum foil paper (used as metal layer) pasted on acrylic sheet (used as dielectric layer with $\varepsilon_{\mathrm{r}}=2.8, \tan \delta=0.02$ and thickness of $2.9 \mathrm{~mm}$ ) forms a metal-dielectric layer. The proposed three layer structure is cascaded with the help of plastic spacers and screw. The dimension of the fabricated FSS layers is $300 \times 300 \mathrm{~mm}^{2}$. Each of the layers contains 64 metallic patch elements. Fabricated layer 1, layer 2, layer 3 and the cascaded structures of the fabricated FSS structure are shown in Fig. 2 (a), (b), (c) and (d), respectively.

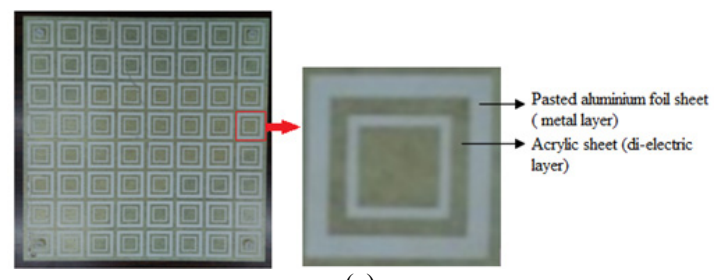

(a)

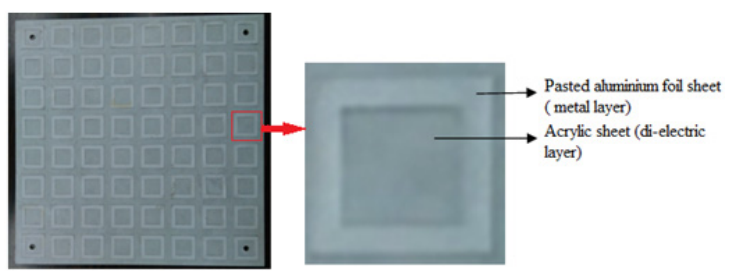

(b)

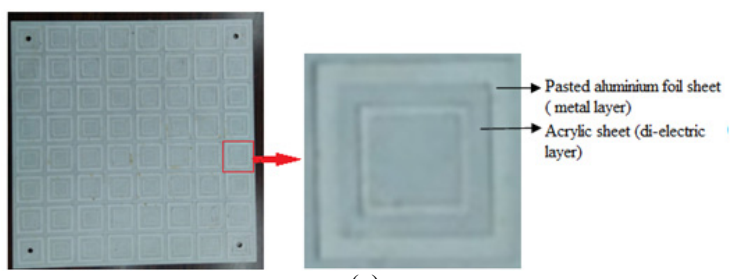

(c)

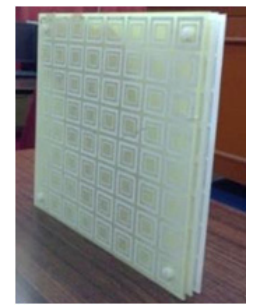

(d)

Fig. 2. (a) Fabricated prototype of layer 1. (b) Fabricated prototype of layer 2. (c) Fabricated prototype of layer 3. (d) The proposed cascaded arrangement of 3 layered fabricated FSS. 


\section{Simulated and Measured Result Analysis}

The full wave EM simulations of individual FSS layer and the cascaded structures are implemented by ANSYS HFSS software (based on Finite Element Method) to obtain their transmission characteristics. Below $-10 \mathrm{~dB}$ reference level in all of the transmission characteristics curve is treated as stop band. Here all the simulations are carried out for normal incidence of the plane wave. Transmission coefficient $\left(\mathrm{S}_{21}\right)$ of FSS layer $1 \& 3$; layer 2 and proposed tri-layered structure as well as the reflection coefficient $\left(\mathrm{S}_{11}\right)$ are shown in Fig. 3. For layer 1 or layer 3, the transmission coefficient $\left(\mathrm{S}_{21}\right)$ with two transmission zeroes, resonated at $2.2 \mathrm{GHz}$ and $5.1 \mathrm{GHz}$ with percentage bandwidth of $36 \%$ and $27 \%$ respectively is obtained. For layer 2, a transmission coefficient with a single stop band at $3.8 \mathrm{GHz}$ with $40 \%$ bandwidth is obtained. Here two square loops in design help to obtain these two stop bands in case of layer 1 and a single square loop in design helps to obtain a single stop band in case of layer 2. The dimensions of these square loops are taken in such a way so that the band range for layer 2 is situated in between two bands, obtained for layer 1. So when these three layers are arranged in cascade manner with maintaining an air gap (D) a wide stop band of $3.60 \mathrm{GHz}$ between frequency ranges of $2.03 \mathrm{GHz}-$ $5.63 \mathrm{GHz}$ is obtained. The percentage bandwidth is increased up to $94 \%$ (measured with respect to the middle frequency of the band). Moreover, as two same designed FSS layers are cascaded (layer 1 and layer 3) a high roll-off in higher and lower cut-off frequency is achieved. Reflection coefficient $\left(\mathrm{S}_{21}\right)$ of the proposed FSS is showing that the throughout the operating bandwidth all the frequencies of the incident wave is totally reflected from the proposed FSS. The roll-off in higher band edge for this transmission characteristics curve is $480 \mathrm{~dB} / \mathrm{GHz}$, whereas the roll-off in lower band edge is $180 \mathrm{~dB} / \mathrm{GHz}$, which makes the transmission characteristics more selective in nature.

As the design of unit cell for each of the layers is symmetric along $x$-axis and $y$-axis, it gives the same frequency behavior for both of the polarizations, i.e. TE and

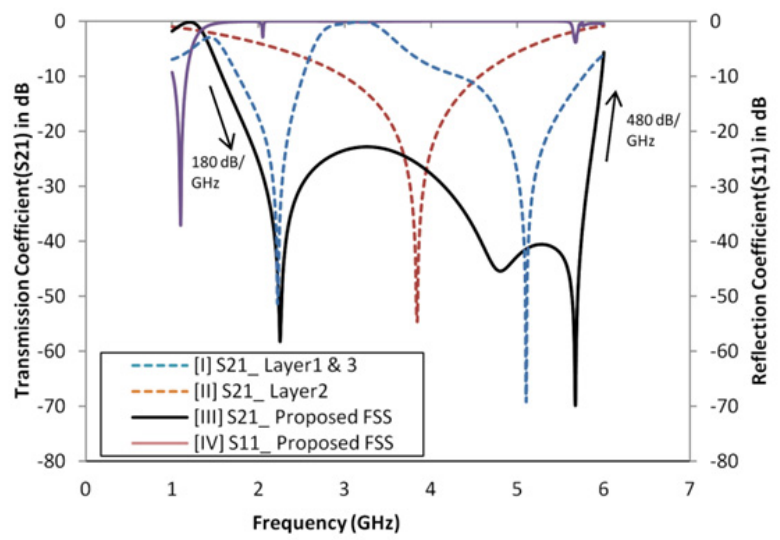

Fig. 3. Simulated transmission coefficient $\left(\mathrm{S}_{21}\right)$ of (I) layer 1 \& 3, (II) layer 2, (III) proposed cascaded 3 layer FSS and reflection coefficient $\left(\mathrm{S}_{11}\right)$ of $(\mathrm{IV})$ the proposed cascaded 3 layer FSS.
TM. For different incident angles for TE and TM mode the simulations are carried out and presented in Fig. 4(a) and Fig. 4(b), respectively. Frequency behavior is same for both TE and TM polarization of incident wave, and it can also be seen from the figures that frequency behavior of the proposed FSS has not been affected significantly up to $40^{\circ}$.

A parametric study is carried out for the 3 layer proposed FSS structure by varying the width of internal air gap (D) between two layers. Simulated frequency behavior of the FSS for different values of D is shown in Fig. 5. It is observed clearly as value of D is increased, the resonating frequency is being shifted towards the higher frequency. This happened because of changing in coupling inductance and capacitance generated for the air gap. The resonating frequency for different widths of the air gaps are mentioned in Tab. 2.

The fabricated prototype of the 3 layer cascaded FSS is shown in Fig. 2(d). The dimensions of the unit cell patch for all of the three layers are presented in Tab. 1 which is discussed earlier. Each of the layers consists of $8 \times 8$, total number of unit cells is 64 . The prototype is fabricated by

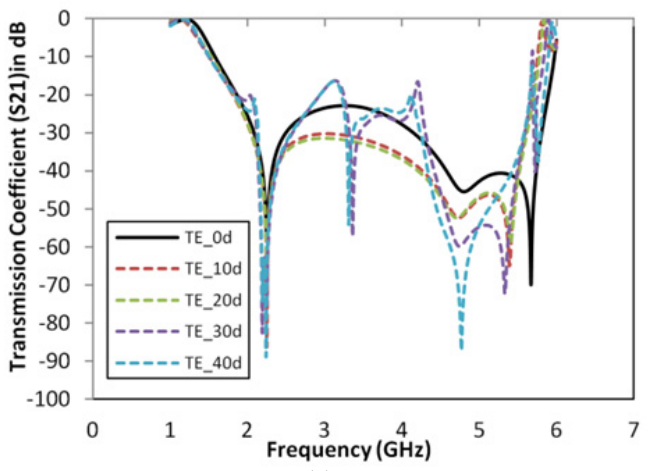

(a)

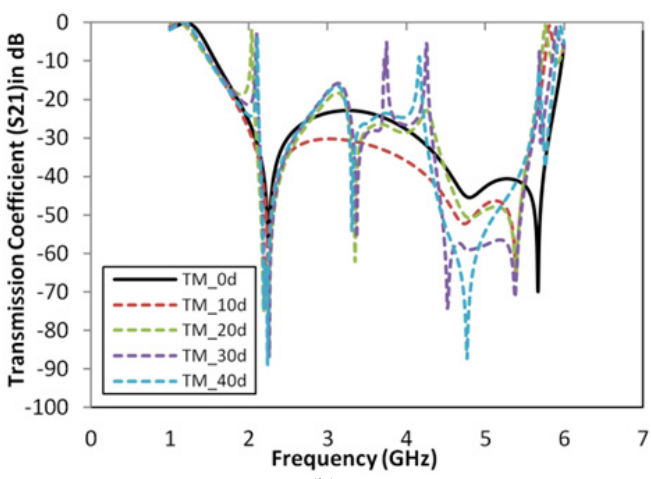

(b)

Fig. 4. (a) Simulated transmission coefficients $\left(S_{21}\right)$ of the proposed FSS structure for different incident angles of the incident TE wave. (b) Simulated transmission coefficients $\left(\mathrm{S}_{21}\right)$ of the proposed FSS structure for different incident angles of the incident TM wave.

\begin{tabular}{|c|c|c|c|c|c|}
\hline D (mm) & 12 & 14 & 16 & 18 & 20 \\
\hline Resonating Frequency (GHz) & 2.05 & 2.34 & 2.40 & 2.47 & 2.64 \\
\hline
\end{tabular}

Tab. 2. Different values of the width of internal air gap (D) between two layers and the corresponding resonating frequency. 


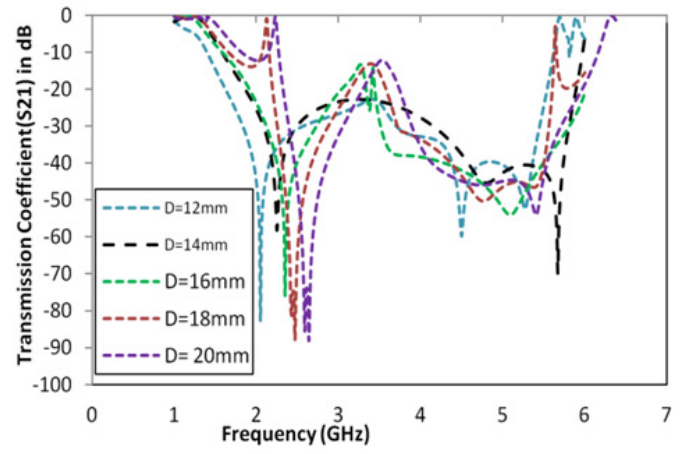

Fig. 5. Simulated transmission coefficients $\left(S_{21}\right)$ of the proposed FSS structure for different values of the widths of internal air gap (D) between two corresponding layers.

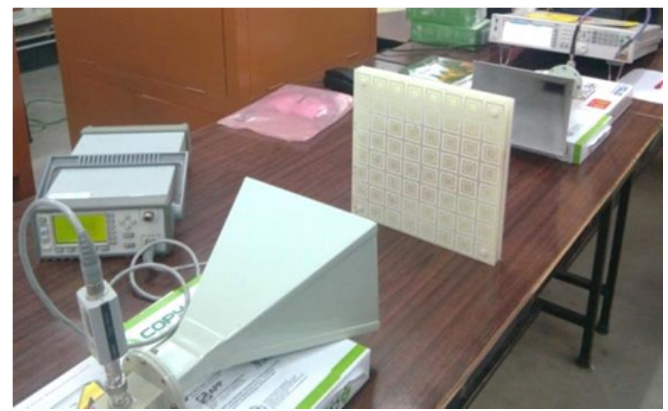

Fig. 6. Photograph of arrangement of full measuring set up of microwave test bench for measuring the transmission characteristics of the fabricated FSS structure.

a very simple method. In measurement set-up the proposed structure is placed between the transmitting and receiving horn antennas. The transmitting antenna is connected with a microwave generator and the receiving antenna is connected with the power meter. The full measuring set-up to measure the transmission characteristics of the proposed FSS on the microwave test bench is shown in Fig. 6. The comparison of the simulated and measured results is shown in Fig. 7. It can be observed that measured data are in well agreement with the simulated result. In Fig. 8 measured transmission coefficients of the proposed FSS by varying the incidence angle of the incident wave up to 40 degree are being presented. From this the incidence angle stabilization of the proposed FSS is verified strongly.

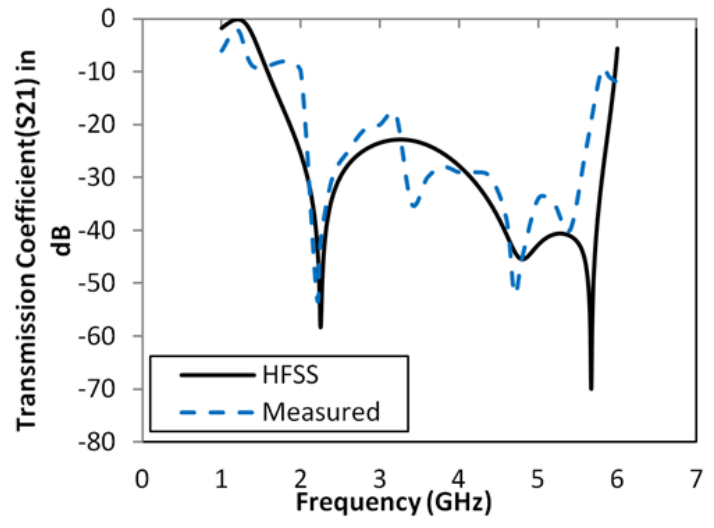

Fig. 7. Comparison of simulated and measured transmission coefficients $\left(\mathrm{S}_{21}\right)$ of the proposed cascaded FSS.

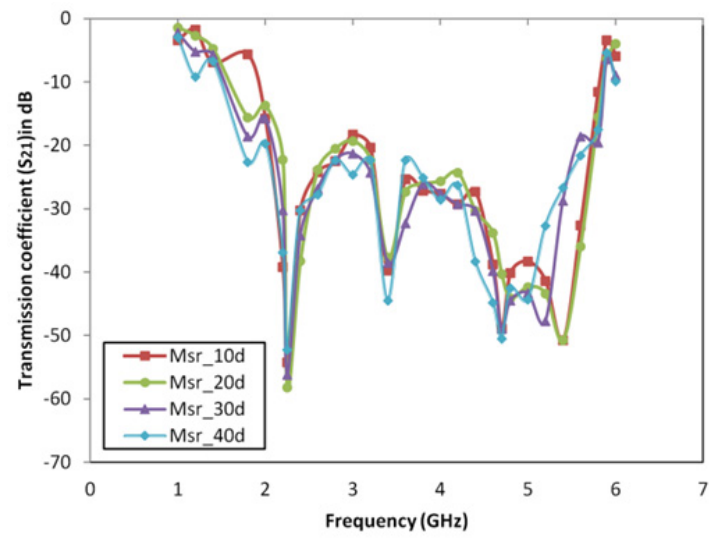

Fig. 8. Measured transmission coefficients $\left(\mathrm{S}_{21}\right)$ of the proposed cascaded FSS for different incident angles $\theta=10^{\circ}, 20^{\circ}, 30^{\circ}$ and $40^{\circ}$.

\section{Equivalent Circuit Model}

The transmission behaviors of the proposed triple layered FSS are also explained hereby with the help of equivalent circuit models (ECM) which are illustrated in Fig. 9. Layer 1 and layer 3 are the same in design and illustrated by the parallel combination of two series resonant circuit formed by components $\left(L_{1}, C_{1}\right)$ and $\left(L_{2}, C_{2}\right)$. The outer square loop is modeled by $L_{1}$ and $C_{1}$ whereas the inner square loop is modeled by $L_{2}$ and $C_{2}$. The values of $L_{1}, L_{2}$, $C_{1}$ and $C_{2}$ are calculated using the following equations [19].

$$
\begin{gathered}
L_{1}=\mu_{0} \frac{d_{3}}{2 \pi}\left[\frac{\ln \left(\csc \frac{\pi w_{1}}{2 d}\right) \ln \left(\csc \frac{\pi w_{2}}{2 d}\right)}{\ln \left(\csc \frac{\pi w_{1}}{2 d} \csc \frac{\pi w_{2}}{2 d}\right)}\right], \\
L_{2}=\mu_{0} \frac{d_{5}}{2 \pi} \ln \left(\csc \frac{\pi w_{2}}{2 d}\right), \\
C_{1}=\varepsilon_{0} \varepsilon_{\mathrm{eff} f}\left[0.75 \cdot 4 \cdot \varepsilon_{\mathrm{r}} \cdot \frac{d_{3}}{2 \pi} \ln \left(\csc \frac{\pi g_{1}}{2 d}\right)\right], \\
C_{2}=\varepsilon_{0} \varepsilon_{\mathrm{eff}} \cdot 4 \cdot \varepsilon_{\mathrm{r}} \cdot \frac{d_{5}}{2 \pi}\left[\frac{\ln \left(\csc \frac{\pi g_{1}}{2 d}\right) \ln \left(\csc \frac{\pi g_{2}}{2 d}\right)}{\ln \left(\csc \frac{\pi g_{1}}{2 d} \csc \frac{\pi g_{2}}{2 d}\right)}\right] .
\end{gathered}
$$

In these equations, $d, d_{3}$ and $d_{5}$ are periodicity of the unit cell, length of the outer loop and length of the inner loop of layer 1 and layer 3, respectively. $w_{1}$ and $w_{2}$ are width of the outer loop and width of the inner loop, respectively. $g_{1}$ and $g_{2}$ are the width of the inter gap of two outer loop and the gap between the outer loop and the inner loop, respectively.

The square loop in the middle layer is modeled by $L_{3}$ and $C_{3}$. The values of $L_{3}$ and $C_{3}$ are calculated from the following equations [20]

$$
L_{3}=\mu_{0} \frac{d_{1}}{2 \pi} \ln \left(\csc \frac{\pi w_{3}}{2 d}\right),
$$




$$
C_{3}=\varepsilon_{0} \varepsilon_{\text {eff }} \cdot \frac{2 d_{1}}{\pi} \ln \left(\csc \frac{\pi g_{3}}{2 d}\right) .
$$

In these equations, $d_{1}, w_{3}$ and $g_{3}$ are length of the square loop, width of the square loop and width of the inter gap between two adjacent square loops on the middle layer.

The dielectric substrate is also modeled as transmission line formed with $L_{\mathrm{T} 1}$ and $C_{\mathrm{T} 1}$ where the value of $L_{\mathrm{T} 1}$ and $C_{\mathrm{T} 1}$ are as follows [21]

$$
\begin{gathered}
L_{T 1}=\mu_{0} \cdot h, \\
C_{\mathrm{T} 1}=\varepsilon_{0} \varepsilon_{\text {eff }} \cdot h .
\end{gathered}
$$

In these equations, $h$ represents the width of the substrate.

The air gap between the two layers is also modeled as transmission line formed with $L_{\mathrm{T} 2}$ and $C_{\mathrm{T} 2}$ where the value of $L_{\mathrm{T} 2}$ and $C_{\mathrm{T} 2}:[21]$

$$
\begin{gathered}
L_{\mathrm{T} 2}=\mu_{0} \cdot D, \\
C_{\mathrm{T} 2}=\varepsilon_{0} \cdot D .
\end{gathered}
$$

Here, $D$ stands for the width of the air gap between the two layers.

For all the cases, $\varepsilon_{0}$ (free space permittivity) is $8.85 \times 10^{-12} \mathrm{~F} / \mathrm{m}, \varepsilon_{\text {eff }}$ (effective permittivity of dielectric) is $\left(\varepsilon_{\mathrm{r}}+1\right) / 2=1.9$ and $\mu_{0}$ (free space permeability) is $4 \pi \times 10^{-7} \mathrm{H} / \mathrm{m}$.

All the calculated values of inductances and capacitances are presented in Tab. 3. Transmission properties $\left(\mathrm{S}_{21}\right)$ of the equivalent circuit shown in Fig. 9 are gotten from ADS software.

The comparison of the simulated transmission characteristics $\left(\mathrm{S}_{21}\right)$ of the proposed FSS observed from HFSS and deduced from equivalent circuit model is shown in Fig. 10. Both of the graphs are in good agreement and verifying the simulated result of the proposed FSS.
A comparative study of the proposed FSS with some recently published articles of same kind of work has been presented in Tab. 4.

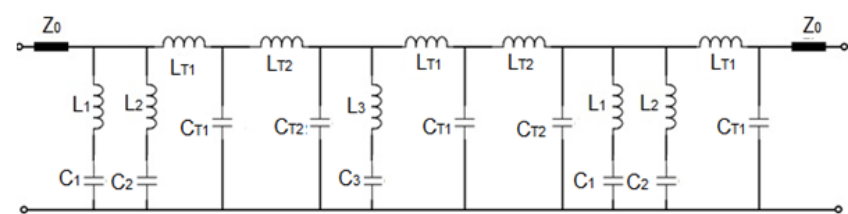

Fig. 9. Equivalent circuit model of the proposed cascaded FSS structure unit cell.

\begin{tabular}{|c|c|c|c|}
\hline Parameter & Value & Parameter & Value \\
\hline$L_{1}$ & $9.6 \mathrm{nH}$ & $C_{1}$ & $0.393 \mathrm{pF}$ \\
\hline$L_{2}$ & $6.3 \mathrm{nH}$ & $C_{2}$ & $0.196 \mathrm{pF}$ \\
\hline$L_{3}$ & $8.4 \mathrm{nH}$ & $C_{3}$ & $0.321 \mathrm{pF}$ \\
\hline$L_{\mathrm{T} 1}$ & $5.6 \mathrm{nH}$ & $C_{\mathrm{T} 1}$ & $0.071 \mathrm{pF}$ \\
\hline$L_{\mathrm{T} 2}$ & $17.7 \mathrm{nH}$ & $C_{\mathrm{T} 2}$ & $0.124 \mathrm{pF}$ \\
\hline
\end{tabular}

Tab. 3. Values of inductors and capacitors of the ECM circuit shown in Fig 9.

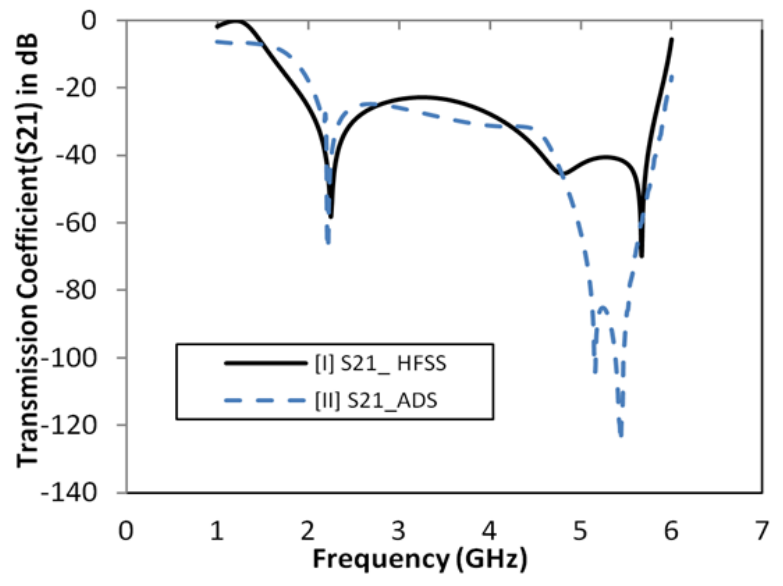

Fig. 10. Comparison of simulated transmission coefficients $\left(\mathrm{S}_{21}\right)$ of the proposed FSS structure (I) by HFSS, (II) by ADS (for ECM).

\begin{tabular}{|l|c|c|c|c|c|}
\hline Parameters & Ref[22]\# & Ref[23] & Ref[24] & Ref[25] & Proposed \\
\hline Frequency Band & $5.9-13.4 \mathrm{GHz}$ & $3.05-10.65 \mathrm{GHz}$ & $40-70 \mathrm{GHz}$ & $6.0-15.0 \mathrm{GHz}$ & $2.06-5.63 \mathrm{GHz}$ \\
\hline Percentage Bandwidth & $87.4 \%$ & $109.4 \%$ & $54.5 \%$ & $85.7 \%$ & $94 \%$ \\
\hline Number of layers & 3 & 2 & 2 & 2 & 3 \\
\hline Layer spacing & $0.17 \lambda_{0}$ & $1.1 \lambda_{0}$ & Not mentioned & $0.1 \lambda_{0}$ & $0.1 \lambda_{0}$ \\
\hline Unit cell dimensions & $0.2 \lambda_{0} \times 0.2 \lambda_{0}$ & $0.3 \lambda_{0} \times 0.3 \lambda_{0}$ & $0.34 \lambda_{0} \times 0.34 \lambda_{0}$ & $0.5 \lambda_{0} \times 0.5 \lambda_{0}$ & $0.2 \lambda_{0} \times 0.2 \lambda_{0}$ \\
\hline Incidence angle stability & Up to 30 degree & Up to 30 degree & Up to 30 degree & Not mentioned & Up to $40 \mathrm{degree}$ \\
\hline Maximum insertion loss & NA & $-43 \mathrm{~dB}$ & $-55 \mathrm{~dB}$ & $-45 \mathrm{~dB}$ & $-70 \mathrm{~dB}$ \\
\hline Minimum insertion loss & NA & $-15 \mathrm{~dB}$ & $-16 \mathrm{~dB}$ & $-15 \mathrm{~dB}$ & $-23 \mathrm{~dB}$ \\
\hline Roll off in lower band edge & $5 \mathrm{~dB} / \mathrm{GHz}$ & $80 \mathrm{~dB} / \mathrm{GHz}$ & $23 \mathrm{~dB} / \mathrm{GHz}$ & $75 \mathrm{~dB} / \mathrm{GHz}$ & $180 \mathrm{~dB} / \mathrm{GHz}$ \\
\hline Roll off in higher band edge & $12 \mathrm{~dB} / \mathrm{GHz} *$ & $10 \mathrm{~dB} / \mathrm{GHz}$ & $6.4 \mathrm{~dB} / \mathrm{GHz}$ & $8 \mathrm{~dB} / \mathrm{GHz}$ & $480 \mathrm{~dB} / \mathrm{GHz}$ \\
\hline Technique used & Cascade & Cascade & Cascade & Cascade & Cascade \\
\hline Tunable and switchable & No & No & No & Yes & Yes \\
\hline
\end{tabular}

Tab. 4. Comparison table of the proposed work with some previous same kind of works.

[* Roll off of the lower band edge and higher band edge of the previous works is not mentioned in their article. These roll offs are calculated from their transmission characteristics curves.

\# in this article, $3 \mathrm{~dB}$ bandwidth of the pass band has been presented in the article where as in rest of all cases $-10 \mathrm{~dB}$ bandwidth has been presented.] 
It can be easily seen the proposed design has good compactness with respect to the previous designs (as unit cell dimension is $0.2 \lambda_{0} \times 0.2 \lambda_{0}$ ). Percentage bandwidth is also very good enough. Insertion loss throughout the operating band is better than other reported works (maximum insertion loss $-70 \mathrm{~dB}$ and minimum insertion loss is $-23 \mathrm{~dB}$ ) and also huge roll-off in lower and higher band edge have been achieved. This type of huge roll-off gives the structure more selectivity of its operating band which is not shown in case of other works. The proposed FSS also has good incident angle stability (up to 40 degree) and polarization independency. Tunability and switchability in frequency behavior offer the proposed FSS structure another dimension of novelty.

\section{Conclusion}

In this paper the design procedure and the analysis on transmission characteristics of an FSS with wide stop band characteristics in the frequency range of $2.06 \mathrm{GHz}$ to $5.63 \mathrm{GHz}$ is presented. The proposed structure contains three layers of patch type FSS arranged in cascade with a certain air gap in between two consecutive layers leading to a low profile design. The proposed design provides bandwidth of around 94\%. Moreover the structure has a good roll-off in higher and lower cut-off frequencies in its transmission characteristics. As the designs of patch elements in each of the layers are symmetric with respect to $x$ and $y$ axes, transmission characteristics remain same for 90 degree rotation of the FSS. Measured data significantly follows the simulated result. The wideband characteristics of this proposed FSS may be useful in enhancing the radiation properties of an antenna with wide band operating frequency. The FSS may also be useful in a dichroic reflector system.

\section{References}

[1] MUNK, B. A. Frequency Selective Surfaces: Theory and Design. John Wiley \& Sons, 2005. DOI:10.1002/0471723770

[2] WU, T. K. (ed.) Frequency Selective Surface and Grid Array. Wiley-Interscience, 1995. ISBN-13: 978-0471311898

[3] ROMEU, J., RAHAMAT-SAMII, Y. Fractal FSS: A novel dualband frequency selective surface. IEEE Transactions on Antennas and Propagation, 2000, vol. 48, no. 7, p. 1097-1105. DOI: $10.1109 / 8.876329$

[4] PIRHADI, A., BAHRAMI, H., NASRI, J. Wideband high directive aperture coupled microstrip antenna design by using a FSS superstrate layer. IEEE Transactions on Antennas and Propagation, 2012, vol. 60, no. 4, p. 2101-2106. DOI: 10.1109/TAP.2012.2186230

[5] LEE, Y. J., YEO, J., MITTRA, R., et al. Design of a frequency selective surface (FSS) type superstrate for dual-band directivity enhancement of microstrip patch antennas. In IEEE Antennas and Propagation Society International Symposium. Washington (USA), 2005, vol. 3, p. 2-5. DOI: 10.1109/APS.2005.1552158

[6] CHATterJeE, A., PARUI, S. K. Gain enhancement of a wide slot antenna using a second-order bandpass frequency selective surface. Radioengineering, 2015, vol. 24, no. 2, p. 455-461. DOI: $10.13164 /$ re.2015.0455

[7] CHATTERJEE, A., PARUI, S. K. Frequency-dependent directive radiation of monopole-dielectric resonator antenna using a conformal frequency selective surface. IEEE Transactions on Antennas and Propagation, 2017, vol. 65, no. 5, p. 2233-2239. DOI: 10.1109/TAP.2017.2677914

[8] THUMMALURU, S. R., KUMAR, R., CHAUDHURY, R. K. Isolation enhancement and radar cross section reduction of MIMO antenna with frequency selective surface. IEEE Transactions on Antennas and Propagation, 2018, vol. 66, no. 3, p. 1595-1600. DOI: 10.1109 /TAP.2018.2794417

[9] SWETHA, A., NAIDU, K. R. Gain enhancement of an UWB antenna based on a FSS reflector for broadband applications. Progress In Electromagnetics Research C, 2020, vol. 99, p. 193-208. DOI: 10.2528/PIERC19120905

[10] SAHA, C., SIDDIQUI, J. Y., ANTAR, Y. M. M. Multifunctional Ultrawideband Antennas: Trends, Techniques and Applications. $1^{\text {st }}$ ed. Boca Raton: CRC Press, 2019. DOI: $10.1201 / 9781351026543$

[11] KAZEMZADEH, A., KARLSSON, A. Multilayered wideband absorbers for oblique angle of incidence. IEEE Transactions on Antennas and Propagation, 2010, vol. 58, no. 11, p. 3637-3646. DOI: 10.1109 /TAP.2010.2071366

[12] RANGA, Y., MATEKOVITS, L., ESSELlE, K. P., et al. Design and analysis of frequency-selective surfaces for ultra wideband applications. In 2011 IEEE EUROCON-International Conference on Computer as a Tool. Lisbon (Portugal), 2011, p. 1-4. DOI: 10.1109/EUROCON.2011.5929186

[13] SEgundo, F. C. G. D. S., CAMPOS, A. L. P. D. S., GOMES NETO, A. A design proposal for ultrawide band frequency selective surface. Journal of Microwaves, Optoelectronics and Electromagnetic Applications, 2013, vol. 12, no. 2, p. 398-409. DOI: $10.1590 / \mathrm{S} 2179-10742013000200012$

[14] RANGA, Y. MATEKOVITS, L., WEILY, A. R., et al. A low-profile dual-layer ultra-wideband frequency selective surface reflector. Microwave and Optical Technology Letters, 2013, vol. 55, no. 6, p. 1223-1227. DOI: 10.1002/mop. 27583

[15] MAJIDZADEH, M., GHOBADI, C., NOURINIA, J. Ultra wide band electromagnetic shielding through a simple single layer frequency selective surface. Wireless Personal Communications, 2017, vol. 95, no. 3, p. 2769-2783. DOI: $10.1007 / \mathrm{s} 11277-017-$ 3960-6

[16] LI, B., SHEN, Z. Three-dimensional bandpass frequency-selective structures with multiple transmission zeros. IEEE Transactions on Microwave Theory and Techniques, 2013, vol. 61, no. 10, p. 3578-3589. DOI: 10.1109/TMTT.2013.2279776

[17] ZHONG, T., ZHANG, H., MIN, X. L., et al. Wideband frequency selective surface with a sharp band edge based on mushroom-like cavity. Progress In Electromagnetics Research Letters, 2016, vol. 62 , p. 105-110. DOI: 10.2528/PIERL16070304

[18] MA, Y., WU, W., YUAN, Y., et al. A high-selective frequency selective surface with hybrid unit cells. IEEE Access, 2018, vol. 6, p. 75259-75267. DOI: 10.1109/access.2018.2878941

[19] LUO, X. F., TEO, P. T., QING, A., et al. Design of double-square-loop frequency-selective surfaces using differential evolution strategy coupled with equivalent-circuit model. Microwave and Optical Technology Letters, 2005, vol. 44, no. 2, p. 159-162. DOI: $10.1002 / \mathrm{mop} .20575$

[20] RODRIGUEZ BARRERA, M. A., CARPES, W. P. Bandwidth for the equivalent circuit model in square-loop frequency selective surfaces. IEEE Transactions on Antennas and Propagation, 2017, vol. 65 , no. 11 , p. 5932-5939. DOI: 10.1109/TAP.2017.2754418

[21] SAHA, S., BEGAM, N., CHATTERJEE, A., et al. Reconfigurable frequency selective surface with tunable characteristics depending 
on intensity of atmospheric light. IET Microwaves, Antennas \& Propagation, 2019, vol. 13, no. 13, p. 2336-2341. DOI: 10.1049/iet-map.2019.0339

[22] ANWAR, R. S., WEI, Y., MAO, L., et al. Miniaturised frequency selective surface based on fractal arrays with square slots for enhanced bandwidth. IET Microwaves, Antennas \& Propagation, 2019, vol. 13, no, 11, p. 1811-1819. DOI: 10.1049/ietmap. 2018.5224

[23] SEgundo, F. C. G. D. S., CAMPOS, A. L. P. D. S., GOMES NETO, A., et al. Double layer frequency selective surface for ultra wide band applications with angular stability and polarization independence. Journal of Microwaves, Optoelectronics and Electromagnetic Applications, 2019, vol. 18, no. 3, p. 328-342. DOI: $10.1590 / 2179-10742019 v 18 \mathrm{i} 31696$

[24] KESAVAN, A., KARIMAN, R., DENIDNI, T. A. A novel wideband frequency selective surface for millimeter-wave applications. IEEE Antennas and Wireless Propagation Letters, 2016, vol. 15, p. 1711-1714. DOI: 10.1109/LAWP.2016.2528221

[25] SARIKA, TRIPATHY, M. R., RONNOW, D. A wideband frequency selective surface reflector for $4 \mathrm{G} / \mathrm{X}$-band/Ku-band. Progress In Electromagnetics Research C, 2018, vol. 81, p. 151-159. DOI: 10.2528/PIERC18010908

\section{About the Authors...}

Snehasish SAHA was born in 1990. He has received his B. Tech. degree in Electronics and Instrumentation Engineering from DETS, University of Kalyani in 2012 and completed his M.Tech. in Communication Engineering from the same university in the year of 2014. Now he is registered Ph.D. scholar in the University of Kalyani and working on reconfigurable passive and active frequency selective surfaces. Till now he has 5 SCI indexed journal papers and about 15 national/international conference papers.

Nurnihar BEGAM was born in 1990. She received B.Tech. in Instrumentation and Control Engineering (ICE) from the Academy of Technology, Hooghly in the year of 2011. She received M.Tech. degree in Communication
Engineering in the Department of Engineering and Technological Studies, University of Kalyani in the year of 2014. She has facilated her Ph.D. from the same department, University of Kalyani, Kalyani, Nadia in 2020. Her research interests include microwave filters, planar and curved frequency selective surface, microstrip antenna. She has authored more than 15 publications in referred journals and conference proceedings. She received the Best Paper Award in NCETAS, West Bengal, India in 2014.

Sushanta BISWAS was felicitated with a Ph.D in Engineering from Jadavpur University in the year 2004. He has obtained his M.E from Jadavpur University in the year 1995. He earned his B.E. degree in Electronics and Telecommunication Engineering from the Bengal Engineering College (presently known as the Bengal Engineering and Science University, Shibpur) in the year 1990. He is presently working as a Scientific Officer (Associate Professor Rank) at the Dept. of Engineering \& Technological Studies, University of Kalyani. His area of research includes microstrip antenna, microstrip filter, frequency selective surfaces, and artificial neural network. He has contributed to numerous research articles in various journals and conferences of repute.

Partha Pratim SARKAR (corresponding author) obtained his Ph.D. in Engineering from Jadavpur University in the year 2002. He has obtained his M.E. from Jadavpur University in the year 1994. He earned his B.E. degree in Electronics and Telecommunication Engineering from the Bengal Engineering College in the year 1991. He is presently working in the rank of Professor in the Department of Engineering and Technological Studies, University of Kalyani, since January 2005. His area of research includes microstrip antenna, frequency selective surfaces, and artificial neural network. He has contributed to numerous (more than 245 publications) research articles in various journals and conferences of repute. He is a life fellow of IETE and fellow of IE (India). 